\title{
Genotype X Environment Interaction for Storage Root Yield in Sweetpotato Under Managed Drought Stress Conditions
}

\author{
Benjamin M. Kivuva ${ }^{1}$, Stephen M. Githiri ${ }^{2}$, George C. Yencho ${ }^{3} \&$ Julia Sibiya $^{4}$ \\ ${ }^{1}$ Kenya Agricultural Research Institute (KARI), Muguga, Nairobi, Kenya \\ ${ }^{2}$ Jomo Kenyatta University of Agriculture and Technology, Nairobi, Kenya \\ ${ }^{3}$ Department of Horticultural Science, North Carolina State University, Raleigh, North Carolina, USA \\ ${ }^{4}$ Rabie Saunders Building, University of Kwa Zulu Natal, Pietermaritzbag, South Africa \\ Correspondence: Benjamin M. Kivuva, Kenya Agricultural Research Institute (KARI), Muguga, Box \\ 30148-00100, Nairobi, Kenya. Tel: 254-720-824-484. E-mail: benmusem@yahoo.com
}

\author{
Received: January 1, 2014 Accepted: February 7, 2014 Online Published: September 15, 2014 \\ doi:10.5539/jas.v6n10p41 URL: http://dx.doi.org/10.5539/jas.v6n10p41
}

\begin{abstract}
Most crops, including sweetpotato vary widely in yield performance across different agro-ecological environments. This study was set up to determine the genotype $\mathrm{x}$ environment interaction (GEI) for storage root yield performance of 24 sweetpotato genotypes in eight environments; two locations - Kiboko and Thika, two moisture stress conditions - drought stress and no drought stress, and two years - 2011 and 2012 in Kenya. Plots of three rows each of 10 plants per genotype, at density of $0.9 \mathrm{~m} \times 0.30 \mathrm{~m}$ were panted during dry season under split plot design replicated twice. Managed irrigation was applied to control moisture stress during the growth period. Fresh storage root yield (FSR) data was collected, and drought susceptibility indices (DSI) determined. Additive Main Effects and Multiplicative Interactions (AMMI) genotype main effect by genotype-environment (GGE) interaction biplots and regression analyses were done using Genstat $14^{\text {th }}$ edition to determine GEI effects. The environment, genotype main effects, and the GEI were all significant $(P<0.001)$. The DSI showed significant variation of genotypes in different environments. The highest yielding genotypes across the environments were G7, G14, G15, and G10 while most stable genotypes were G5, G22 and G2 and the least stable was G24. Thus, genotypes G5, G22 and G2 may be used across environments, while genotypes G7 and G14 could be used, 1) in specific locations to boost production under unpredictable rainfall conditions, 2) incorporated into drought screening breeding programmes to develop a new generation of drought tolerant sweetpotato varieties to meet changing climatic conditions.
\end{abstract}

Keywords: biplot analysis, drought stress, genotype environment interaction, stability, storage root yield

\section{Introduction}

The ability of crop varieties to withstand drought stress varies across the world (Walters, Farrant, Pammenter, $\&$ Berjak, 2002). Several factors including the micro and macro environment of a crop, growth stage, time and severity of drought affect the ability of the crop to tolerate drought stress (Boonjung \& Fukai, 1996). Drought stress may occur during the initial crop growth stage, the reproductive stage or may be intermittent over the growth period of the crop (Mohammadi \& Amri, 2013). A crop variety that withstands the fluctuating water stresses may be termed as stable and thus drought tolerant (Ekanayake, 1990).

Sweetpotato is an important root crop in the world and it has been reported to be drought tolerant. However the crop is sensitive to drought stress during establishment and storage root initiation periods (Ekanayake, 1990; Lewthwaite \& Triggs, 2012). Drought at the storage root initiation stage causes small sized storage root formation thereby negatively affecting the crop yields (Makihara, Tsuda, Hirai, \& Kuroda, 1999). Sweetpotato storage root yield is a product of the number of plants per unit area, number of storage root per plant, and the weight of the storage roots, which may vary across environments. The number of plants per unit area depends on number of vines planted and the number that establish and survive to maturity. The number of the storage roots and their sizes depend on the genotype planted and its rooting structure which is influenced by prevailing environmental conditions (Lewthwaite \& Triggs, 2012).

Large genotype $(\mathrm{G})$ x Environment (E) interactions make identification of superior genotypes difficult (Sullivan, 
Yan, \& Prive', 2002). Thus, varieties need to be evaluated in different environments before they are released to determine their stability (Mohammadi \& Amri, 2013). Drought resistance is generally controlled by quantitative traits influenced by the environment. Therefore, pre-release selection trials must be conducted in more than one season or location prior to release to determine their potential value (Mohammadi \& Amri, 2013). The selected genotypes are further tested on a large scale to determine their stability and their commercial viability. The association of drought tolerance with morphological, physiological and chemical traits, all controlled by different genes, complicate environmental effects on genotype across locations (Lisar, Motafakkerazad, Mosharraf, \& Rahman, 2012). Managing irrigation to simulate farmer's field conditions but allowing sufficient levels of water stress to distinguish drought and susceptible genotypes is a useful methodology employed to screen for and develop crops resistant to drought. Typically, soil moisture content is monitored using percent dry weight, tensiometers, or neutron probes (Amede, Kimani, Ronno, Lunze, \& Mbikay, 2004). In the tropics, where rainfall is often bimodal and the rains begin and end in a defined time-frame, another useful strategy to evaluate drought tolerance incorporates delayed sowing after the onset of rains so the crop is challenged to yield during the ensuing dry period (Singh, Malhotra, Halila, Knights, \& Verma, 1994).

Drought alters sink-source relationship by affecting assimilate production, translocation and partitioning (Lisar et al., 2012). Translocation is less affected by water stress than photosynthesis and respiration (Boyer, 1976). Therefore, terminal drought exposes the ability of a genotype to translocate reserves to the sink (Ludlow and Muchow, 1990). Genotypes subjected to drought stress continually for some time and in different environments, express their ability to tolerate drought stress (Amede et al., 2004). If these genotypes are tested in multiple environments their stability may be determined through AMMI and GGE biplot analysis (Choukan, 2011; Sullivan et al., 2002; Yan, Kang, Ma, Woods, \& Cornelius, 2007). For example, in upland rain fed conditions, deep-rooted sweetpotato varieties that continue to grow by tapping water from deeper layers may be suitable. Also, genotypes with roots with the capacity to penetrate the hardpan layer of compacted soil at about $20-25 \mathrm{~cm}$ below the soil surface in low land areas are selected (Champoux et al., 1995; Ray et al., 1996). However, information on which sweetpotato genotypes are suitable for which agro-ecological zone is lacking in Kenya.

Genotypes stable across environments in many cases may be drought tolerant (Lisar et al., 2012). Thus, it is vital for the breeder to establish the stability of varieties over different environmental conditions. Even though sweetpotato is regarded as drought tolerant, the crop loses a substantial amount of its potential yield in times of slight drought especially during the storage root bulking stage (Agili, Nyende, Ngamau, \& Masinde, 2012; Lewthwaite \& Triggs, 2012). Moisture stress also triggers sweetpotato weevil infestation as weevils typically become more active during the onset of drought and cracks that develop in the soil as a result of drought enable them to feed on the developing storage roots. This sequence of events can lead to total loss of the crop (Lewthwaite \& Triggs, 2012).

Clearly, the determination of genotype by environment interaction effects on drought tolerance of sweetpotato varieties is essential prior to variety release and/or their use in a breeding program. This study established a series of experiments and conducted AMMI, GGE biplot and regression analyses of 24 diverse sweetpotato genotypes across eight environments to determine their genotype $\mathrm{x}$ environment interaction effects for drought tolerance, and yield and quality characteristics.

\section{Materials and Methods}

\subsection{Plant Materials}

Twenty four genotypes of varying origins were used in this study. The genotypes were comprised of two local varieties (local checks), promising breeding lines, released varieties, and local landraces (Table 1). The genotypes were selected on the basis of their yielding ability and drought tolerance for possible inclusion into a crossing block focused on breeding for drought tolerance. 
Table 1 . The genotypes used in the study and their source

\begin{tabular}{|c|c|c|c|}
\hline Genotype ID & Genotype name & Source & Status \\
\hline G1 & 189151.38 & Peru & CIP clone \\
\hline G2 & 189150.1 & Peru & CIP clone \\
\hline G3 & 1990621 & Peru & CIP clone \\
\hline G4 & 422656 & Peru & Breeders clone \\
\hline G5 & 441725 & Peru & Breeders clone \\
\hline G6 & 194573.9 & Peru & CIP clone \\
\hline G7 & 194555.7 & Peru & Breeders clone \\
\hline G8 & 194515.15 & Peru & CIP clone \\
\hline G9 & 421066 & Peru & CIP clone \\
\hline G10 & 420014 & Peru & CIP clone \\
\hline G11 & A56 & South Africa & Breeders clone \\
\hline G12 & $\mathrm{A} 2$ & South Africa & Breeders clone \\
\hline G13 & Beaureguard & USA & Released clone \\
\hline G14 & Chingovu & Mozambique & Improved clone \\
\hline G15 & Excel & Peru & USDA ARS germplasm release \\
\hline G16 & 48 Gabagaba & Mozambique & Breeders clone \\
\hline G17 & Lodha & Kenya & Landrace \\
\hline G18 & Nyatonge & Kenya & Landrace \\
\hline G19 & Resisto & USA & Released variety \\
\hline G20 & Sinia & Kenya & landrace \\
\hline $\mathrm{G} 21$ & Tanzania & Uganda & Landrace \\
\hline $\mathrm{G} 22$ & Unawazambane06-01 & Mozambique & Breeders cultivar \\
\hline G23 & W119 & USA & USDA ARS germplasm release \\
\hline G24 & Xiadla-Xa-Kau & Mozambique & Breeders clone \\
\hline
\end{tabular}

\subsection{Locations}

The experiments were conducted at the two sites namely: Kenya Agricultural Research Institute (KARI)-Kiboko, and KARI-Thika. KARI-Kiboko research station is located at Makueni county, $187 \mathrm{~km}$ east of Nairobi, at latitude $2^{\circ} 15^{\prime}$, longitude $37^{\circ} 45^{\prime} \mathrm{E}$ and altitude $993 \mathrm{~m}$ asl. The research station is classified under agro-ecological zone five and receives mean annual rainfall of $548 \mathrm{~mm}$ with long-term annual average rainfall of $615 \mathrm{~mm}$ and is ideal for dry land research. The station receives bimodal rainfall with the more reliable short rains season falling in October to January $(328 \mathrm{~mm})$ and the less reliable rains season from March to May $(233 \mathrm{~mm})$. The annual mean maximum temperature is $30.6{ }^{\circ} \mathrm{C}$, while the annual mean minimum temperature is $17.4{ }^{\circ} \mathrm{C}$ which translates to annual mean temperature of $24{ }^{\circ} \mathrm{C}$. The soils are of rhodic ferrasols to ferric luvisols on the old peneplain and eutric fluvisol at the bottom of the river valley (Mwacharo, Okeyo, Kamande \& Rege, 2004).

KARI-Thika is located $75 \mathrm{~km}$ north east of Nairobi, latitude $0^{\circ} 59^{\prime}$ South, longitude $37^{\circ} 04^{\prime}$ East, and altitude $1548 \mathrm{~m}$ asl. The area receives bimodal mean rainfall of about $1000 \mathrm{~mm}$ annually with long rains of $142 \mathrm{~mm}$ falling March to May and the short rains of $116 \mathrm{~mm}$ falling in October to December. The areas has minimum temperature of $13.7{ }^{\circ} \mathrm{C}$, maximum of $25.1{ }^{\circ} \mathrm{C}$, and mean annual temperature of $19.4{ }^{\circ} \mathrm{C}$ (Ndegwa, Muchui, Wachuri, \& Kimamira, 2009).

\subsection{Field Evaluations}

The experimental design was a split plot, laid in randomised complete block design (RCBD), where irrigation status was main plot and genotypes were the subplot. The experimental plots were three rows of 10 plants with $0.9 \mathrm{~m}$ between rows and $0.30 \mathrm{~m}$ between plants. The planting material was taken from presumably virus-free 
mother plants grown in greenhouses at KARI, Muguga. Two water regime levels, drought stress and no drought stress were tested. Double ammonium phosphate fertilizer was applied at the rate of $50 \mathrm{~kg} \mathrm{P}_{2} \mathrm{O}_{5} \mathrm{ha}^{-1}$ at planting. The experiments were planted late in the season to increase the probability of increased drought pressure in the life span of the crop. Data were collected from six centrally placed hills of every experimental plot. Harvesting was done at 150 days after planting (DAP). Data on number of storage roots, storage root fresh and dry matter, storage root yield per plot was taken. Also, storage root composite samples of $200 \mathrm{~g}$ (fresh weight) and vine composite samples of $500 \mathrm{~g}$ (fresh weight) were taken for dry-matter determination.

Table 2. Description of the test environments during the four cropping seasons at KARI Kiboko and Thika

\begin{tabular}{llllll}
\hline Env & Site & Status & Planting dates & Harvesting dates & Soil type \\
\hline E1 & Kiboko & Rain fed & $24 / 11 / 2010$ & $24 / 04 / 2011$ & rhodic ferrasols \\
E2 & Kiboko & Irrigated & $24 / 11 / 2010$ & $24 / 04 / 2011$ & rhodic ferrasols \\
E3 & Thika & Rain fed & $26 / 11 / 2010$ & $26 / 04 / 2011$ & ferric luvisols \\
E4 & Thika & Irrigated & $26 / 11 / 2010$ & $26 / 04 / 2011$ & ferric luvisols \\
E5 & Kiboko & Rain fed & $10 / 12 / 2011$ & $10 / 05 / 2012$ & rhodic ferrasols \\
E6 & Kiboko & Irrigated & $10 / 12 / 2011$ & $10 / 05 / 2012$ & rhodic ferrasols \\
E7 & Thika & Rain fed & $15 / 12 / 2011$ & $15 / 05 / 2012$ & ferric luvisols \\
E8 & Thika & Irrigated & $15 / 12 / 2011$ & $15 / 05 / 2012$ & ferric luvisols \\
\hline
\end{tabular}

Where Env = environment.

\subsection{Tensiometer Calibration}

Six tensiometers were placed into 10 litre pots filled with sterile soil and watered to field capacity. The pots were allowed one hour for the water to infiltrate into the soil uniformly after which two samples from each pot were taken at tensiometer reading zero and moisture content determined. To do this, a five $\mathrm{cm}$ diameter by five $\mathrm{cm}$ height core sample was used to obtain soil samples from the pots containing the tensiometers. The amount of water in the core samples was gravimetrically determined and related to the tensiometer centibar readings to calibrate the soil moisture readings. Moisture loss was monitored using the tensiometers by taking two samples from each pot at readings; $5,10,15,20,25,30,35,40,45,50,55,60,65,70$ and 75 centbars and moisture loss determined. The data was used to calibrate the tensiometers readings taken from the field. A calibration curve of:

$$
\mathrm{Y}=0.1079 \mathrm{x},
$$

at $\mathrm{R}^{2}=0.96$ was fitted on a scatter graph drawn using the data. The tensiometers were installed in the field at 30 $\mathrm{cm}$ deep in the soil during planting of the field experiment and used to monitor soil moisture stress status. Using the calibration curve fitted equation, the tensiometers readings were converted to moisture deficit in the field relative to field capacity (reading 0 ). Under irrigation treatment in the field, irrigation water was applied once the tensiometers read 15 cent bars which signify the permanent wilting point in most crops (O'Geen 2012; Table 3). Where no rainfall occurred during planting and up to a month after planting, such as E3 and E5, under rainfed treatment, irrigation water was applied to avoid death of the plants. After establishment of the crop, plots under rainfed treatments were not irrigated even when the tensiometer readings were beyond 15 cent bars to ensure persistent moisture stress, however, the occasional poor rainfall could reverse slightly the moisture stress (Table 3). Also growing degree units (GDU) were estimated as:

$$
\mathrm{GDU}=\frac{\mathrm{Tmax}+\mathrm{Tmin}}{2}-\text { Tbas }
$$

using base temperature of $10^{\circ} \mathrm{C}$ (Wang, Rich, \& Price, 2003).

\subsection{Statistical Analysis}

The data on storage root yield for all locations and seasons were combined to give a total of eight environments (locations $\mathrm{x}$ season $\mathrm{x}$ year) and analysed using AMMI and GGE biplots and regression analyses. A combined analysis of variance (ANOVA) for root yield data was done in GenStat $14^{\text {th }}$ edition to determine the effects of environment (E) [combining the effects of season (S), location (L), and S x L interaction], genotype (G), and all possible interactions among the factors. 
The mean values of genotypes for each experiment were used to analyse the relationships among genotypic yields under moisture stress and non-moisture stress environments. The model used was:

$$
Y_{i j}=\mu+G_{i}+E_{j}+G_{i j}
$$

Where $\mathrm{Y}_{\mathrm{ij}}$ is the corresponding variable of the $\mathrm{i}^{\text {th }}$ genotype in $\mathrm{j}^{\text {th }}$ environment (location), $\mu$ is the total mean, $G_{i}$ is the main effect of $i^{\text {th }}$ genotype, $E_{j}$ is the main effect of $j^{\text {th }}$ environment, $G_{i j}$ is the effect of genotype $x$ environment interaction.

Drought stress index (DSI) was estimated as:

$$
\mathrm{DSI}=\left(1-\frac{Y_{\mathrm{S}}}{Y_{\mathrm{P}}} / 1-\frac{\overline{Y_{\mathrm{S}}}}{\overline{Y_{\mathrm{P}}}}\right)
$$

(Fischer \& Maurer, 1978), where Ys and Yp are the storage root yield of a genotype under drought stress and no drought stress conditions, respectively.

AMMI was used to analyse and interpret genotype x environment interaction (Zobel, Wright, \& Gauch, 1988). The AMMI model equation is as follows:

$$
\mathrm{Y}_{\mathrm{ij}}=\mu+\mathrm{g}_{\mathrm{i}}+\mathrm{e}_{\mathrm{j}}+\sum_{k=1}^{t} \lambda_{\mathrm{k}} \alpha_{\mathrm{ik}} \gamma_{\mathrm{jk}}+\varepsilon_{\mathrm{ij}}
$$

Where; $Y_{i j}$ is the cell mean in the $i^{\text {th }}$ genotype and $j^{\text {th }}$ environment, $\mu$ is the overall mean $g_{i}$ and $e_{j}$ are the main effects of genotype and environments, and $\varepsilon_{\mathrm{ij}}$ is the experimental error. Residuals of the $\mathrm{ij}$ th ${ }^{\mathrm{i}}$ cell, $Z_{\mathrm{ij}}=Y_{\mathrm{ij}}-\mathrm{Y}_{\mathrm{i} .}-\mathrm{Y}_{\mathrm{j}}$ $+\mathrm{Y}$ form a matrix Z. The least square estimate of the AMMI parameters $\lambda_{\mathrm{k}}$ is the singular value of the $\mathrm{n}^{\text {th }}$ PCA axis, $\alpha_{i k}$ and $y_{j k}$ are the scores for $i^{\text {th }}$ genotype and $j^{\text {th }}$ environment. The AMMI model was adjusted depending on the number of principal components (PC) considered. In this study two PC's were factored in therefore, the model was adjusted to:

$$
\mathrm{Y}_{\mathrm{ij}}=\mu+\mathrm{g}_{\mathrm{i}}+\mathrm{e}_{\mathrm{j}}+\lambda_{1} \alpha_{\mathrm{i} 1} \mathrm{y}_{\mathrm{j} 1}+\lambda_{2} \alpha_{\mathrm{i} 2} \mathrm{y}_{\mathrm{j} 2}+\varepsilon_{\mathrm{ij}}
$$

which considered the main effects in addition to IPCA1 and IPCA2 for non-additive variation (Gauch, 1992)

The GGE biplot analysis used the following model:

$$
\mathrm{Y}_{\mathrm{ij}}-\mu-\mathrm{E}_{\mathrm{j}}=\lambda_{1} \varepsilon_{1} \eta_{1 \mathrm{j}}+\lambda_{2} \varepsilon_{2} \eta_{2 \mathrm{j}}+\mathrm{e}_{\mathrm{ij}}
$$

where $\mathrm{Y}_{\mathrm{ij}}$ is the corresponding variable of the $\mathrm{i}^{\text {th }}$ genotype in $\mathrm{j}^{\text {th }}$ environment (location), $\mu$ is the total mean, $\mathrm{E}_{\mathrm{j}}$ is the main effect of $\mathrm{j}^{\text {th }}$ environment, $\lambda_{1}$ and $\lambda_{2}$ are singular values of principal components PC1 and PC $2 ; \varepsilon_{\mathrm{i} 1}$ and $\varepsilon_{\mathrm{i} 2}$ are eigen vectors in $\mathrm{j}^{\text {th }}$ environment (location) for PC1 and PC2 of $\mathrm{i}$ genotype in $\mathrm{j}$ environment. The GGE biplots were constructed by plotting the first two principal components $\left(\mathrm{PC}_{1}\right.$ and $\left.\mathrm{PC}_{2}\right)$ derived from subjecting environment centred yield data to singular value decomposition (Yan et al., 2000). In the biplot, the best genotypes in each environment and groups of environments were identified through a polygon view (Yan et al., 2000) that was drawn by connecting genotypes that were furthest from the biplot origin such that all genotypes were enclosed within the polygon. Perpendicular lines were then drawn to each side of the polygon starting from the biplot origin.

The GGE biplot was also used to explore the interrelationships among environments by constructing lines (environment vectors) from the biplot origin to markers for the environments. The correlation coefficient between any two environments was approximated by the cosine of the angle between their vectors. Acute angles showed a positive correlation; obtuse angles showed a negative correlation and right angles no correlation (Yan $\&$ Kang, 2003). The length of the vector described the discriminating ability of the environment (Yan et al., 2007; Choukan, 2011; Sibiya, Tongoona, \& Derera, 2013). Another line called the average environment axis (AEC) was also used to show the ranking of the genotypes by their mean yield and stability. The line passed through the biplot origin and another line perpendicular to it was drawn to represent the stability of the genotypes. According to Yan (2002), either direction away from the biplot origin on this axis, indicated greater GEI and reduced stability.

Genotypic stability was determined using linear regression model by Eberhart and Russell (1966):

$$
Y i j=\mu+b i I j+\delta i j+\varepsilon i j
$$

where; $\mathrm{Y}_{\mathrm{ij}}$ is the mean for the genotypes $\mathrm{i}$ at location $\mathrm{j} ; \mu$ is the general mean for genotype $\mathrm{i}$; $b i$ is the regression coefficient for the $\mathrm{i}^{\text {th }}$ genotype; $I j$ is the mean deviation from the overall mean for all genotypes at a particular location; $\delta i j$ is the deviation from regression for the $\mathrm{i}^{\text {th }}$ genotype at the $\mathrm{j}^{\text {th }}$ location; and $\varepsilon i j$ is the mean experimental error. 


\section{Results}

\subsection{Climatic Data}

The amount of rainfall received during the first experiment (October 2010/February 2011) was $201.3 \mathrm{~mm}$ at Kiboko and $32.6 \mathrm{~mm}$ at Thika. During the second experiments (April 2011/ August 2012, Kiboko received $8 \mathrm{~mm}$ and Thika $229 \mathrm{~mm}$, and this was not sufficient for crop growth. Supplementary irrigation water was applied at both sites and seasons as follows; E1 $(0 \mathrm{~mm}), \mathrm{E} 2(280 \mathrm{~mm}), \mathrm{E} 3(60 \mathrm{~mm}), \mathrm{E} 4(340 \mathrm{~mm})$, E5 $(60 \mathrm{~mm})$, E6 $(360$ $\mathrm{mm})$, E7 $(0 \mathrm{~mm})$ and E8 $(280 \mathrm{~mm})$. Details of the supplementary irrigation frequencies are shown in Table 2. The day degree units and relative humidity were higher in Kiboko (season one: 15.25 and season two: 13.15) than in Thika (season one: 9.7 and season two: 10.7) (Table 3).

Table 3. The temperature, rainfall, irrigation water and soil moisture loss of the test environments during the cropping seasons

\begin{tabular}{cccccccccc}
\hline Env & Min & Max & mean & DDU & $\mathrm{R}(\mathrm{mm})$ & $\mathrm{I}(\mathrm{mm})$ & \%RH & SML 4WAP & SML harvesting \\
\hline E1 & 17 & 33 & 25.3 & 15.4 & 201.0 & 0.0 & 78.9 & 3.4 & 573.5 \\
E2 & 17 & 33 & 25.3 & 15.4 & 201.0 & 280.0 & 78.9 & 2.2 & 33.9 \\
E3 & 14 & 26 & 16.2 & 9.7 & 32.6 .0 & 60.0 & 67.5 & 2.2 & 449.6 \\
E4 & 14 & 26 & 16.2 & 9.7 & 32.6 & 340.0 & 67.5 & 1.5 & 19.6 \\
E5 & 16 & 31 & 23.2 & 13.2 & 8.0 & 60.0 & 77.9 & 3.4 & 551.4 \\
E6 & 16 & 31 & 23.2 & 13.2 & 8.0 & 360.0 & 77.9 & 2.1 & 27.6 \\
E7 & 13 & 28 & 20.7 & 10.7 & 229.0 & 0.0 & 57.6 & 2.4 & 412.7 \\
E8 & 13 & 28 & 20.7 & 10.7 & 229.0 & 280.0 & 57.6 & 1.9 & 13.4 \\
\hline
\end{tabular}

Env $=$ environment as described in Table $2, \max =$ maximum, DDU $=$ day degree units, $\mathrm{R}=$ rainfall, $\mathrm{I}=$ irrigation water, $\% \mathrm{RH}=\%$ relative humidity, SML4WAP $=$ soil moisture loss four weeks after planting.

\subsection{Combined AMMI Analysis of Variance}

The AMMI analysis of variance for storage root yield revealed that genotype (G), environment (E) and genotype environment interaction (GEI) effects were significantly different $(P<0.05)$ (Table 4$)$. The treatments $(\mathrm{G}$ and E) and GEI accounted for $95 \%$ of the total variation, with $\mathrm{E}$ accounting for the highest amount of variation (75.2\%), followed by G (11.1\%) and GEI (9\%). The interaction principal component one (IPCA1) accounted for $77.7 \%$ while principal component two (IPCA2) accounted for $6.1 \%$ of the GEI variation sum of squares (Table 4).

Table 4. Source of variation, mean squares and significance, and their contribution to total variation of the genotypes

\begin{tabular}{lllll}
\hline Source of variation & df & MS & $\begin{array}{l}\% \text { contribution to } \\
\text { total variation }\end{array}$ & $\begin{array}{l}\% \text { contribution to } \\
\text { GEI variation }\end{array}$ \\
\hline Total & 383 & 0.253 & 100.0 & \\
Treatments (G,E,GEI) & 191 & $0.487^{* * *}$ & 95.8 & \\
Genotypes (G) & 23 & $0.469^{* * *}$ & 11.1 & \\
Environments (E) & 7 & $10.418^{* * *}$ & 75.2 & \\
Block & 8 & $0.024 \mathrm{~ns}$ & 0.002 & \\
Interactions (I) & 161 & $0.057^{* * *}$ & 9.0 & 77.7 \\
IPCA1 & 29 & $0.247^{* * *}$ & 7.3 & 6.1 \\
IPCA2 & 27 & $0.022 \mathrm{~ns}$ & 0.6 & \\
Residuals & 105 & $0.014 \mathrm{~ns}$ & 1.5 & \\
Error & 184 & 0.021 & 4.0 & \\
\hline
\end{tabular}

Where $* * *=$ significant at $\mathrm{P}<0.001, \mathrm{~ns}=$ not significant. 


\subsection{Genotypic Yield Performance in the Test Environments}

Genotype means indicated that storage root yield varied significantly among genotypes in each test environment (Table 5). The best three genotypes under drought stress environment were G7, G3, and G22; while, the best three genotypes under no drought stress environment were G14, G15, and G7. Genotypes G7, G14 G13, G15 and G10 did well in the drought stress and no drought stress environments. The checks used in this experiment, G18 and G20, performed much lower compared to the best clones (Table 5). The drought stress index (DSI), and percent yield reduction (\%YR), confirmed that the responses of genotypes to drought stress differed with environments. Genotypes G8, G7, G22, G24, G23, G5, G9, and G10 had DSI scores <1 (Table 5).

Table 5. Storage root yield $\left(\mathrm{kg}\right.$ plant $\left.^{-1}\right)$ of sweetpotato genotypes in the specific environments and their DSI values

\begin{tabular}{|c|c|c|c|c|c|c|c|c|c|}
\hline \multirow{2}{*}{ Genotype } & \multicolumn{2}{|c|}{ Drought environment } & \multicolumn{2}{|c|}{ Irrigated environment } & \multicolumn{2}{|c|}{ Across environments } & \multirow{2}{*}{$\% \mathrm{YR}$} & \multirow{2}{*}{ OY } & \multirow{2}{*}{ DSI } \\
\hline & Kiboko & Thika & Kiboko & Thika & Drought & Irrigated & & & \\
\hline G1 & 0.23 & 0.3 & 1.5 & 1.43 & 0.27 & 1.46 & -81.8 & 0.87 & 1.08 \\
\hline G2 & 0.24 & 0.32 & 1.16 & 1.06 & 0.28 & 1.11 & -74.9 & 0.70 & 0.99 \\
\hline G3 & 0.29 & 0.24 & 0.99 & 1.06 & 0.27 & 1.02 & -74 & 0.65 & 0.87 \\
\hline G4 & 0.3 & 0.33 & 1.18 & 1.2 & 0.31 & 1.19 & -73.6 & 0.75 & 0.95 \\
\hline G5 & 0.22 & 0.33 & 0.99 & 0.99 & 0.28 & 0.99 & -72.1 & 0.64 & 0.98 \\
\hline G6 & 0.08 & 0.13 & 1.23 & 1.29 & 0.1 & 1.26 & -91.9 & 0.68 & 1.22 \\
\hline G7 & 0.51 & 0.65 & 1.59 & 1.48 & 0.58 & 1.53 & -62.3 & 1.06 & 0.82 \\
\hline G8 & 0.31 & 0.21 & 0.51 & 0.4 & 0.26 & 0.45 & -42.6 & 0.36 & 0.49 \\
\hline G9 & 0.31 & 0.29 & 1.54 & 1.5 & 0.3 & 1.52 & -80.4 & 0.91 & 0.97 \\
\hline G10 & 0.53 & 0.34 & 1.34 & 1.29 & 0.44 & 1.31 & -66.8 & 0.88 & 1.06 \\
\hline G11 & 0.19 & 0.18 & 1.5 & 1.49 & 0.18 & 1.49 & -87.9 & 0.84 & 1.16 \\
\hline G12 & 0.31 & 0.28 & 1.19 & 1.36 & 0.3 & 1.27 & -76.7 & 0.79 & 1.01 \\
\hline G13 & 0.32 & 0.35 & 1.48 & 1.53 & 0.33 & 1.5 & -78 & 0.92 & 1.03 \\
\hline G14 & 0.35 & 0.31 & 1.53 & 1.59 & 0.33 & 1.56 & -78.9 & 0.95 & 1.05 \\
\hline G15 & 0.34 & 0.21 & 1.59 & 1.52 & 0.27 & 1.56 & -82.4 & 0.92 & 1.09 \\
\hline G16 & 0.11 & 0.15 & 0.64 & 0.68 & 0.13 & 0.66 & -79.9 & 0.40 & 1.06 \\
\hline G17 & 0.22 & 0.25 & 0.85 & 1 & 0.23 & 0.93 & -74.8 & 0.58 & 0.99 \\
\hline G18 & 0.28 & 0.2 & 0.94 & 0.97 & 0.24 & 0.96 & -75 & 0.60 & 0.99 \\
\hline G19 & 0.3 & 0.24 & 1.01 & 1.05 & 0.27 & 1.03 & -74.2 & 0.65 & 0.98 \\
\hline G20 & 0.47 & 0.18 & 0.98 & 1.04 & 0.33 & 1.01 & -67.7 & 0.67 & 0.97 \\
\hline G21 & 0.28 & 0.21 & 1.15 & 1.06 & 0.25 & 1.1 & -77.6 & 0.68 & 1.03 \\
\hline G22 & 0.35 & 0.34 & 1.11 & 0.91 & 0.34 & 1.01 & -65.9 & 0.68 & 0.85 \\
\hline G23 & 0.26 & 0.37 & 1.01 & 0.97 & 0.32 & 0.99 & -68.1 & 0.66 & 0.89 \\
\hline G24 & 0.23 & 0.25 & 0.77 & 0.92 & 0.24 & 0.84 & -71.9 & 0.54 & 0.92 \\
\hline Mean & 0.29 & 0.28 & 1.15 & 1.16 & 0.28 & 1.16 & 74.14 & & 0.98 \\
\hline LSD & 0.07 & 0.06 & 0.06 & 0.05 & 0.049 & 0.061 & 5.157 & & 0.06 \\
\hline$\% \mathrm{CV}$ & 21.9 & 19.6 & 20.3 & 17.7 & 43.4 & 13.3 & 17.3 & & 17.3 \\
\hline
\end{tabular}

Where; \% $\% \mathrm{R}=$ percent yield reduction, $\mathrm{OY}=$ Overall mean yield, DSI $=$ drought stress index.

The AMMI analysis ranked genotypes G7, G14, G3, G15, G10, G20, G22, G23, G13 and G11, as the best across the environments. Among them; G7 and G14 were superior in performance across the environment (Table 6). 
Environment E5 had the lowest IPCA score, which, indicated that GEI was low in that environment confirmed by the low variance of 0.03. Environment E6 had the highest IPCA scores and also high variance, while E5 had the lowest variance. In this study, E6 was the highest yielding site (no drought stress) but unstable, while E5 was lowest yielding but stable site (drought stress) (Table 6).

Table 6. Genotype performance for storage root yield $\left(\mathrm{kg} \mathrm{plant}^{-1}\right)$ and ranking of the first four AMMI selections in each test environment

\begin{tabular}{cccccccccc}
\hline \multirow{2}{*}{ Env. } & \multirow{2}{*}{ Mean } & Variance & Ipca 1 Effects & Ipca 2 Effects & IPCA Score & \multicolumn{4}{c}{ Rank } \\
\cline { 7 - 10 } & & & & & & & & & \\
E1 & 0.32 & 0.03 & 0.51 & -0.37 & 0.47 & G7 & G20 & G3 & G22 \\
E2 & 1.14 & 0.11 & -0.47 & -0.13 & -0.47 & G15 & G14 & G10 & G7 \\
E3 & 0.27 & 0.03 & 0.50 & -0.13 & 0.50 & G7 & G3 & G20 & G22 \\
E4 & 1.17 & 0.10 & -0.50 & 0.38 & -0.50 & G14 & G15 & G7 & G10 \\
E5 & 0.28 & 0.02 & 0.16 & 0.01 & 0.46 & G7 & G3 & G14 & G23 \\
E6 & 1.17 & 0.21 & 0.50 & 0.03 & -0.52 & G14 & G7 & A56 & G13 \\
E7 & 0.28 & 0.11 & 0.47 & 0.23 & 0.5 & G7 & G3 & G14 & G23 \\
E8 & 1.15 & 0.10 & -0.48 & -0.28 & -0.48 & G15 & G10 & G14 & G13 \\
\hline
\end{tabular}

Env $=$ environment as described in Table 2.

\subsection{AMMI GE and IPCA Scores Biplot}

An AMMI biplot was drawn with IPCA scores of genotypes and environment against their respective means (Figure 1). In the biplot, genotypes with IPCA scores close to zero were G12, G13, G1, G2, G22 and G5. Genotypes with a negative IPCA score such as G8 did well under the environments with negative IPCA scores such as E3 and vice versa. The stable high yielding genotypes were G1, G10, and G13 while the least stable genotypes included G24 and G8 (Figure 1).

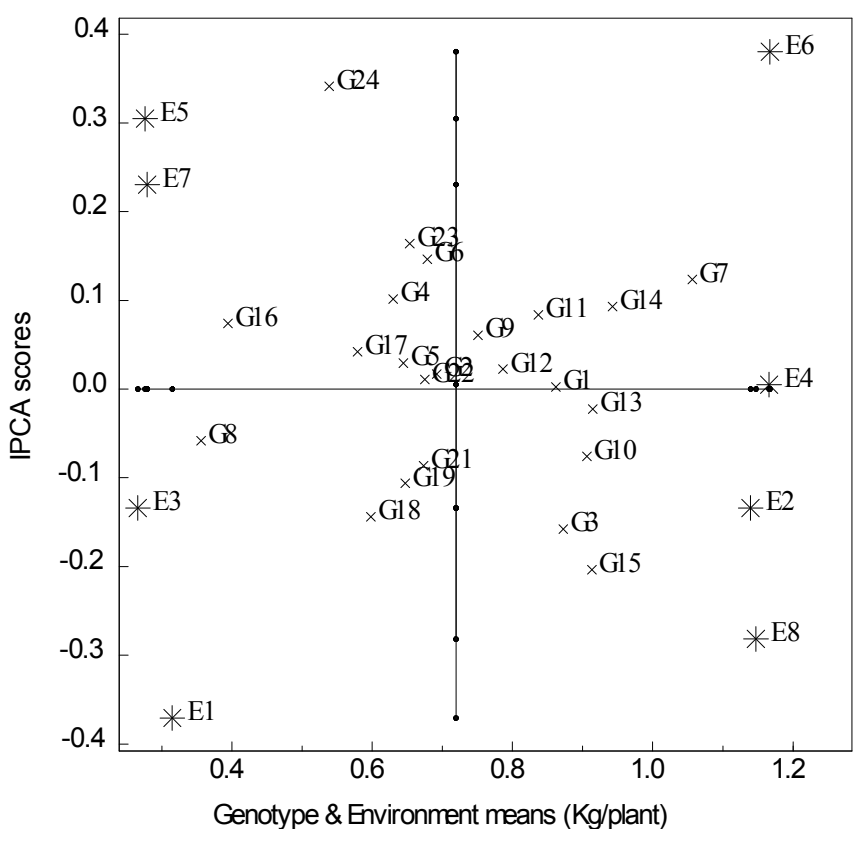

Figure 1. Genotype and environment IPCA2 scores and means based on storage root yield for the eight test environments. The genotypes and environments are as given in Tables 1 and 2, respectively 


\subsection{GGE Biplot Analysis}

The two PCs in the GGE biplot explained $90.80 \%$ of the total GGE variation, where PC1 $=82.99 \%$, and PC2 $=$ $7.81 \%$ (Figure 2). Yield and stability of genotypes was estimated using the average environment coordinates (AEC) method (Yan, 2001; Yan \& Hunt, 2001). From the polygon view, genotypes G7, G14, G15 and G11 were high yielding while G8, G16 and G24 were low yielding. The rays (continuous lines from centre) of the biplot divided the plot into seven sections, with the eight environments appearing in three sectors (Figure 2). The environments were divided into three mega environments (Figure 2).

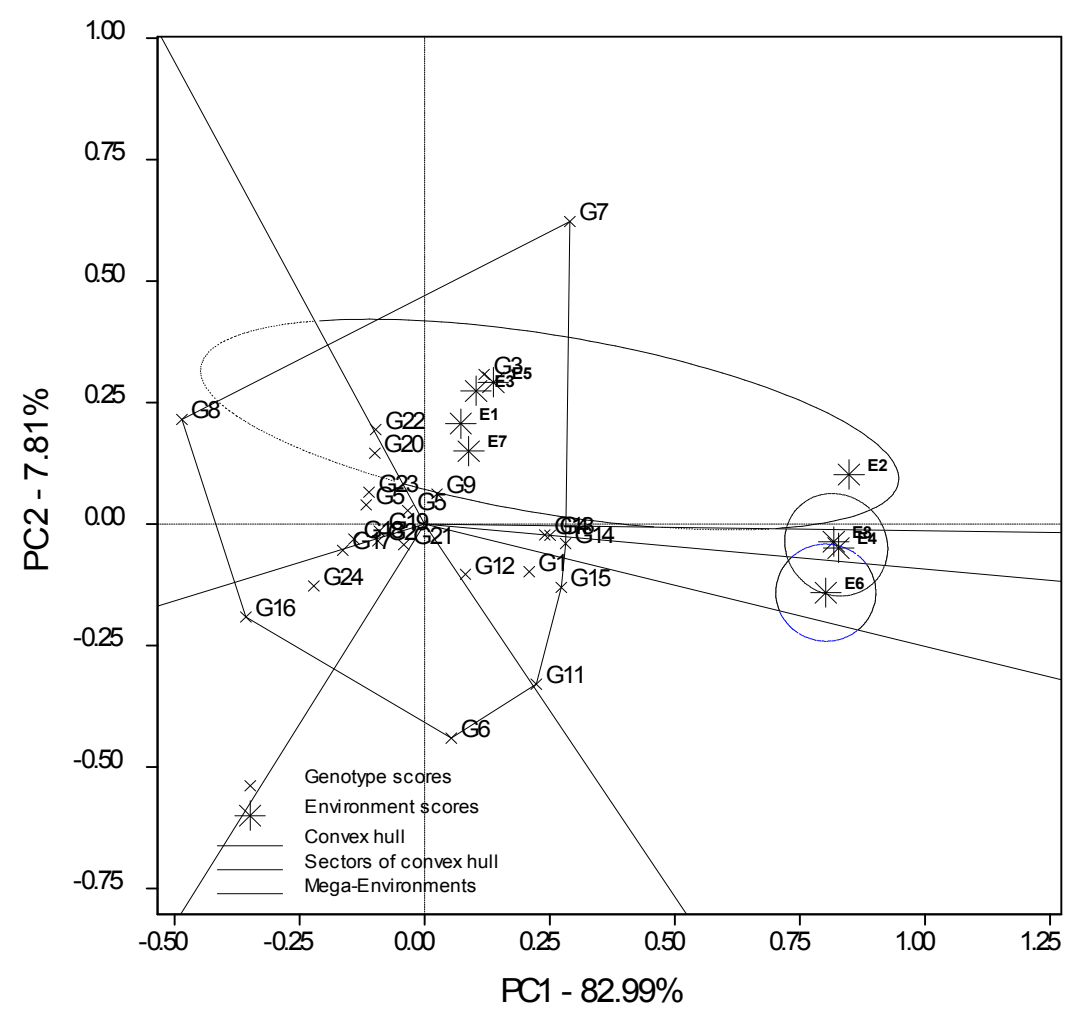

Figure 2. Polygon view of the GGE biplot based on the storage root yield for eight environments. The genotypes and environments are as given in Tables 1 and 2, respectively

\subsection{Ranking GGE Biplot}

GGE biplot analysis also enabled visual assessment of yield performance of PC1 and PC2 of the genotypes for the all environments as presented in a circle (Figure 3). From the circular view, genotypes with the highest nominal yield were G7, G3, G9, G22, G20, G1, and G4, and the lowest were G16, G11, G6, and G8. 


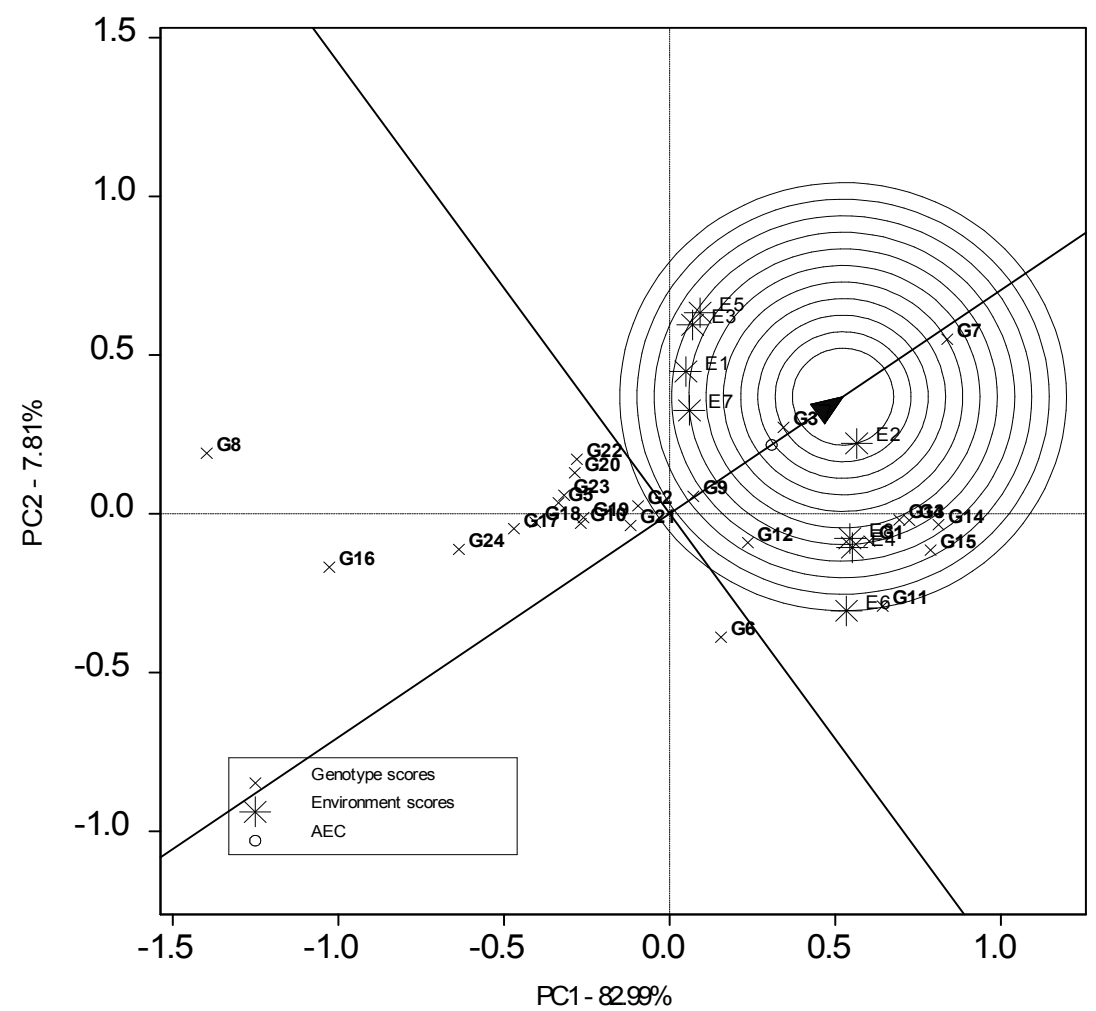

Figure 3. Circular view of the GGE biplot based on the storage root yield for eight environments

\subsection{Regression Analysis}

Genotypes close to the regression curve were G13 (A56), G12 (A2), G5 (194573.9), G9 (441725), G4 (194555.7), and G10 (199062.1. Genotypes G7 (421066), G6 (420066), G11 (48 Gabagaba), G3 (194515.15) and G16 (Excel) were further away from the regression line (Figure 4).
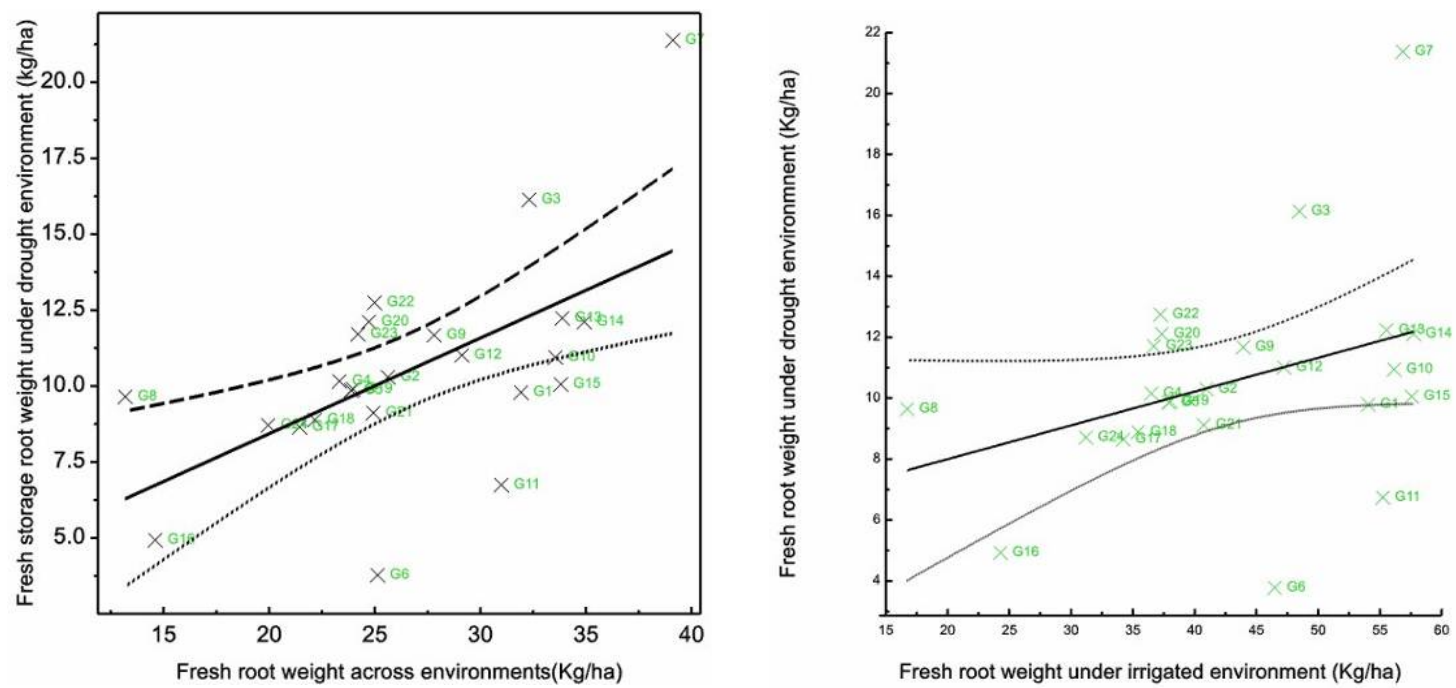

Figure 4. Graphs showing the regression of fresh storage root weight under drought with (a) fresh root weight across environments and (b) Fresh root weight under irrigated environment

\subsection{Relationship Between Environments}

The inter-relationship among environments was plotted in a GGE biplot and all environments had positive PC1. The angles between them revealed that the environments were divided into two groups, drought stress (E1, E3, 
E4 and E5 and no drought stress (E8, E2, E6, E7) (Figure 5). The length of the environment vector also approximated the standard deviation within each environment and drought stress environments were distinctively apart from no drought stress environments. The most discriminative environments were the no drought stress and the least were the drought stress. The angle between the average environment coordinate line and the environment vector determined the stability of the environment; in this study, the most stable environment were E5 and E6 (Figure 5).

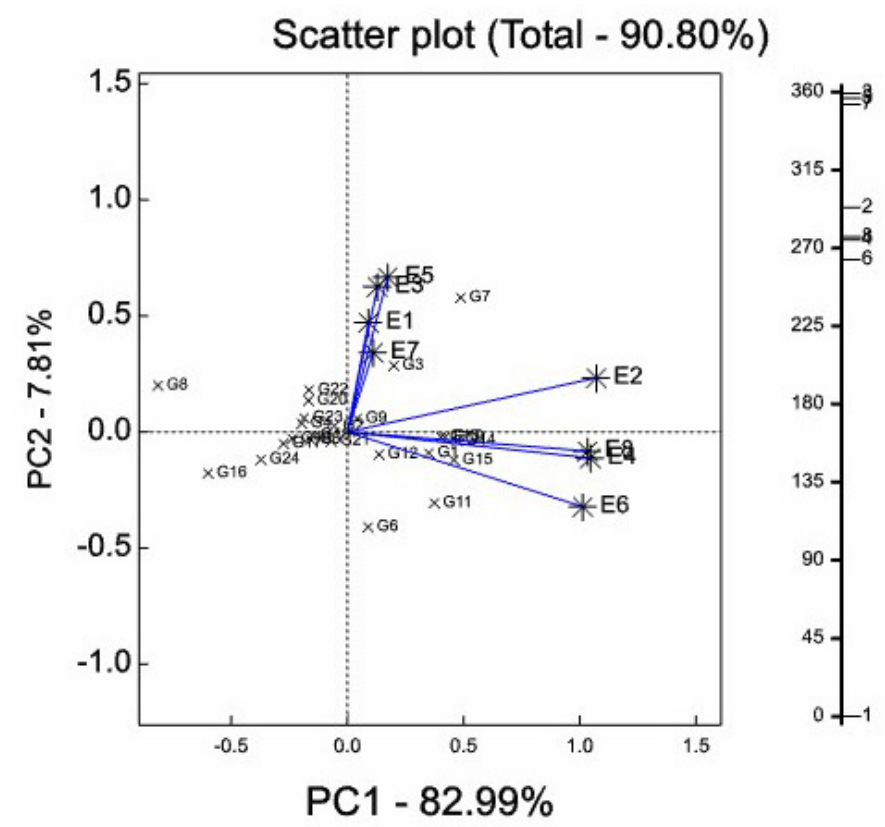

Figure 5. Environment focused scaling GGE biplot based on the storage root yield for eight environments, with $360^{\circ}$ positioning scale based on $\mathrm{PC} 1$ indicated on the right

\section{Discussion}

\subsection{Climatic Data}

The rainfall received was not sufficient for sweetpotato growth indicating the environments were fit for the drought screening study. Also, the mean day degrees units for Kiboko were $14.4{ }^{\circ} \mathrm{C}$ and Thika was $10.2{ }^{\circ} \mathrm{C}$ indicating that, the minimum daily temperature approximated to $20^{\circ} \mathrm{C}$ (Table 2) which is relatively good for sweetpotato growth although not optimal. Mohammadi et al. (2013) in their work reported that, rainfall and temperature were the main environmental factors that had greater impact on GEI occurrence.

\subsection{AMMI Analysis on Genotype Performance Across Environments}

In this study, the AMMI 2 model (G + E + IPCA1 + IPCA2) accounted for $94.2 \%$ of the total variation suggesting that the model fitted well. Genotypes G7 and G14 had high root yield across the eight environments tested, an indication that they were stable and widely adapted. In crop breeding programmes genotypes are tested across varied sites and locations to determine their yield performance and scope of adaptation (Bantayehu, 2009; Hagos \& Abay, 2013). Moreover, AMMI IPCA scores indicated the stability of the environments in terms of genotypes evaluated. Environment E5 had the lowest IPCA score, and low variance an indication that it was the best site for the evaluation of the genotypes for drought stress. This was in contrast to E6 that had the highest IPCA scores and variance, indicating the site had high discrimination for the genotypes and would be good to screen genotypes for specific adaptation. Favourable test environments have large IPCA1 scores and near zero IPCA2 scores (Kaya et al., 2006; Rashidi, Farshadfar, \& Jowkar, 2013). Environments E5 and E6 are located at Kiboko, which is a site for drought screening experiments. These findings are in agreement with Bantayehu (2009) who reported that genotypes had small deviation from the mean in stable environments unlike in unstable environments. He also grouped the experimental sites into high yielding with high GEI and low GEI.

There were large differences in root yield, mostly due to differences in environment and genotype effects. The genotypes with high yields under no drought stress condition which had DSI scores $<1$ could be ranked as 
drought tolerant. Some of the genotypes with high yields under no drought stress also tended to yield well under drought stress conditions over the four cropping seasons. Additionally, the ranking of genotypes based on DSI, showed that the responses of genotypes to drought stress are not consistent over years. Thus, the DSI indicator was able to discriminate different genotypes at each cropping season, depending on the type of drought stress that occurred and the development stage of the crop. Therefore, cultivars for drought tolerance need to be evaluated across environments to select for drought tolerance. This also suggests that breeding for specific adaptation in drought tolerance may be required. Lewthwaite and Triggs (2012) conducted similar work using twelve sweetpotato cultivars in new Zealand and reported three responses due to drought stress. In their study some clones had significant yield reduction, others had no change, while others, interestingly, had increased yields. This implies that, selecting for drought tolerance in breeding programmes, require diverse screening sites. However, high discriminating sites may be used to select site specific tolerant cultivars.

\subsection{AMMI GE and IPCA Scores Biplot}

Genotypes with positive IPCA 1 scores in the AMMI biplot (Figure 2) were high yielding; while those on the left side were low yielding. Nominal yield on the $\mathrm{X}$-axis is indicative of genotype adaptability, and allows evaluation of genetic responses to yield stability and adaptation based on IPCA scores (Mohammadi \& Amri, 2013). The AMMI biplot revealed genotypes that performed better in one environment than in another, which implies that there was a specific interaction between genotypes and environments. Genotypes with IPCA values near zero demonstrated broader adaptability, while genotypes with IPCA1 values far from zero could be suitable for the environment with IPCA1 values of the same sign. Therefore, assessment of individual genotype performances was related to their positions relative to $\mathrm{X}$ and $\mathrm{Y}$ axis. The best genotypes were considered to be those that have high yield with stable performance in most environments. Of the six high yielding genotypes (G7, G14, G13, $\mathrm{G} 15, \mathrm{G} 10, \mathrm{G} 3$ ), genotype $\mathrm{G} 7$ was the highest yielding across the environments.

\subsection{GGE Biplot Analysis}

A polygon view of the GGE biplot revealed the highest yielding genotypes for each environment and clustered the environments. According to Kaya et al. (2006), a succinct summary of genotype performance on different environments in multi environment yield trial can be demonstrated by a display of GGE polygon view biplot. In this study, the rays (continuous lines from the centre) of the biplot divided the plot into seven sections, with the eight environments appearing in three sectors. According to Yan et al. (2007), when different environments fall into different sectors, it implies that they have different high yielding cultivars (susceptible or tolerant) for those sectors and it shows crossover GEI suggesting that the test environments could be divided into mega-environments. In this study, the environments fell in three interacting mega environments indicating significant crossover interaction. The cultivars far from the origin of the polygon had high yield in the environments close to them, and the cultivars close to the origin were more stable across the environments. According to Yan et al. (2000), genotypes within the polygon, especially those located near the plot origin, were less responsive than the vertex genotypes. The environments were divided in three mega environments clustered into two groups of the optimal environments and the moisture stressed environments.

In a similar finding, Sullivan et al. (2002) evaluated three varieties of red raspberry (Heritage, Autumn Bliss, \& Redwing) in 17 year by location environments using GGE biplot analysis and grouped the environments into 2 mega environments on the basis of the performance of the varieties Autumn Bliss and Redwing. They also found environmental variability was responsible for within and between genotype variations. Furthermore, Choukan (2011) performed AMMI and GGE biplot analysis on 14 inbred lines of maize in 5 diverse locations on basis of grain yield, and identified the most suitable inbred for each environment. The environments were then grouped into three mega-environments and the most discriminative environments to the genotypes as well as the most and the least responsive maize inbred lines were determined.

\subsection{GGE Ranking Biplot for Stability and Yield}

The GGE biplot analysis also enabled visual assessment of genotype performance, where average values of PC1 and PC2 of the genotypes for the all environments were presented in a ranking GGE biplot. In the GGE biplot, performance of different genotypes was revealed by the relations of the genotypes and the average environment coordinate (AEC) axis whereby, genotypes in the direction of the arrow of AEC are high yielding. The line which passes through the circle and the origin of the plot is called the average environment axis (AEA) (Yan, 2001; Yan \& Hunt, 2001). The line, which is perpendicular to the AEA line and passes through the origin, is called the average ordinate environment (AOE). This line divides the genotypes into those with higher yield than average (to the right of it) and into those with lower yield than average (on its left side). By projecting the genotypes on AEA axis, the genotypes are ranked by yield, where the yield increases in the direction of the arrow. 
In this study, the highest nominal yield had genotypes G7, G3, G9, G24, G20, G1, and G4, and the lowest were G16, G11, G6, and G8. Stability of the genotypes depends on their distances from the AE abscissa. Genotypes closer to abscissa are more stable than others. Also, in this study, genotypes G2, G5 and G22 were stable. Agili et al. (2012) reported genotype G5 was stable across varying moisture regimes. The circular representation of GGE biplot also enables identification of an ideal genotype. In GGE biplots, ideal genotypes are expected to have high mean productivity (PC1) and more stability (PC2 near zero) (Mohammadi \& Amri, 2013). Thus, an "ideal" genotype is one that has the highest yield across test environments and ranks the highest in all test environments (Kaya et al., 2006). Although, such an "ideal" genotype may not exist in reality, it can be used as a reference for genotype evaluation. The closest to the "ideal" genotype in this study was G3. Moreover, genotype located closer to the "ideal" genotype (G3) was also more desirable.

\subsection{Regression Analysis}

Genotypes close to the regression curve (G13, G9 and G10) were stable, however genotypes further away from the regression (G7, G6 and G16) were unstable.

\subsection{Comparison of Yield and Stability of Genotypes Using the Different Methods Used}

The genotypes that performed well in both drought and no drought environment based on mean yield analysis (G7, G14, G13, G10, G15), also, did well in the AMMI biplot analysis, however, among them, only G7 and G10 had DSI $<1$. Local check G20 had DSI $<1$ and performed well under AMMI biplot analysis. Based on AMMI biplot analysis genotypes G10 and G13 were stable and high yielding while G24 and G8 which had DSI $<1$ were unstable and low yielding. The GGE biplot showed G1 and G13 as stable similar to AMMI biplot while G8 and G24 unstable similar to AMMI biplot. Ranking by GGE biplot indicated that G7, G3, G22, G20 and G1 as among the highest yielding genotypes similar in AMMI and GGE biplot analysis. Also based on ranking by GGE biplot, G8 and G16 ranked lowest similar in GGE and AMMI biplots. Genotypes G10, G12 and G13 appeared stable based on AMMI, GGE biplots and regression analysis. However, the comparison of the yield and stability of genotypes between various methodologies used in this study showed that drought tolerant genotypes were not necessarily high yielding or stable. Furthermore, high yielding genotypes were not necessarily drought tolerant or stable. Moreover, there were slight disparities in discriminating genotype stability and performance between the AMMI, GGE biplots and regression across environments which may be attributed to their different procedures and formulae for their plotting and computation.

\subsection{Relationship Among Test Environments Using GGE Biplots}

All the environments had positive PC1 scores indicating high drought tolerance scores and good drought tolerance discriminative ability. The environments could be grouped into two based on drought tolerance expression and discrimination groups of the genotypes; E2, E4, E6, E8 and E1, E3, E5, E7. The second group was close to zero and comprised of environments under drought stress indicating that under such conditions, drought tolerance discrimination was poorer than under no drought stress environment. Genotypes with disproportionately large positive interactions in some environments and large negative interactions in others have crossover GEI (Kaya et al., 2006). The cosine of the angle between the environment vectors is related to their correlation coefficient; whereby the smaller the angle between them, the higher the correlation (Choukan, 2011). In this study, the inter-relationship between environments revealed that the environments were divided into two groups, drought stress (E1, E3, E5 and E7 and no drought stress (E2, E4, E6, E8) (These environments are described in Table 2). The length of the environment vector also approximates the standard deviation within each environment and is a measure of the discriminating ability of the environment. The most discriminative environments were the no droughts stress and the least were drought stress in this study. The angle between the average environment coordinate line and the environment vector determines whether the environment is stable (representative or not) (Choukan, 2011). Environments located furthest from the biplot origin were the most discriminating of the cultivars. Thus, of the eight environments, E2 had highest drought tolerant expression discrimination (high positive PC1 scores, longest vector) than the others. It appears, therefore, that one site under no drought stress and another site under no drought stress either in Kiboko or Thika could be used for preliminary drought screening after which multisite trials can be conducted.

\section{Conclusion}

Rainfall was low in all the locations and seasons and thus the sites were suitable for screening for drought tolerance. In Kiboko the day degrees were higher than in Thika while the relative humidity was higher in Kiboko than in Thika, a situation that seemed to have equalized evapo-transpiration in both sites. The combined ANOVA showed that environmental effects contributed to the highest variation of $72.5 \%$, an indication that screening the genotypes for GxE effects was vital. The GGE and AMMI biplot clearly showed that some genotypes had high 
yields in particular environments (specific interaction) between genotypes and environments while others had high yields across environments (stable genotypes). This implies the genotypes varied in their ability for drought tolerance. Clones revealed as stable under the AMMI biplot also were found stable under regression e.g. G10 and G13 as well the unstable G8. The GGE polygon view and ranking GGE biplots indicated the stable but low yielding clones e.g. the high yielding unstable clones were G7, G11, while stable high yielding were G10 and G13. Thus, evaluation programme for drought tolerance genotypes need to factor in evaluation across environments while selecting drought tolerance clones for wide or narrow environments. The biplots also indicated the stability levels of the cultivars and the environment. AMMI and GGE biplots are necessary in describing the test sites and the genotype performance across tests sites. This implies that, selecting for drought tolerance in breeding programmes, require diverse screening sites. However particular sites can be used to select site-specific tolerant cultivars.

\section{Acknowledgements}

I deeply appreciate the Director, KARI for allowing me to undertake this study, AGRA for offering me the scholarship through African Centre for Crop Improvement (ACCI), based at university of Kwa Zulu Natal, International Potato Centre for technical support during the study and technicians at KARI Muguga South for their technical field support during the study. Lastly, I greatly appreciate my academic supervisors for their guidance.

\section{References}

Agili, S., Nyende, B., Ngamau, K., \& Masinde, P. (2012). Selection, yield evaluation, drought tolerance indices of orange fleshed sweetpotato (Ipomoea batatas Lam) hybrid clone. Journal of Nutrition and Food Science, 2,138. http://dx.doi.org/10.4172/2155-9600.1000138

Amede, T., Kimani, P., Ronno, W., Lunze, L., \& Mbikay, N. (2004). Coping with drought: strategies to improve genetic adaptation of common bean to drought prone regions of Africa. Network on Bean Research in Africa, International Centre for Tropical Agriculture (CIAT). CIAT Occasional Publication Series, 38, 1-39. Retrieved from http:// www.ncbi.nlm.nih.gov/pmc/articles/PMC3589705

Bantayehu, M. (2009). Analysis and correlation of stability parameters in malting barley. African Crop Science Journal, 17, 145-153.

Boonjung, H., \& Fukai, S. (1996). Effects of soil water deficit at different growth stages on rice growth and yield under upland conditions.2. Phenology, biomass production and yield. Field Crop Research, 48, 47-55. http://dx.doi.org/10.1016/0378-4290(96)00039-1

Boyer, J. S. (1976). Photosynthesis at low water potentials. Philosophical Transactions of the Royal Society, London Biological Sciences, 273, 501-512. http://dx.doi.org/10.1016/0378-4290(96)00039-1

Champoux, M. C., Wang, G., Sarkarung, S., Mackill, D. J., O'Toole, J. C., Huang, N., \& McCouch, S. R. (1995). Locating genes associated with root morphology and drought avoidance in rice via linkage to molecular markers. Theoretical and Applied Genetics, 90, 969-981. http://dx.doi.org/10.1007/BF00222910

Choukan, R. (2011). Genotype, environment and genotype $\times$ environment interaction effects on the performance of maize (Zea mays L.) inbred lines. Crop Breeding Journal, 1, 97-103.

Ekanayake, I. J. (1990). Evaluation of potato and sweetpotato genotypes for drought resistance. CIP Research Guide, 19, 1-16.

Fischer, R., \& Maurer, R. (1978). Drought resistance in spring wheat cultivars. I. Grain yield responses. Australian Journal of Agriculture Research, 29, 897-912. http://dx.doi.org/10.1071/AR9780897

Gauch, H. G. (1992). Statistical analysis of regional yield data: AMMI analysis of factorial designs. Amsterdam, Elsivier.

Hagos, H. G., \&Abay, F. (2013). AMMI and GGE biplot analysis of bread wheat genotypes in the northern part of Ethiopia. Journal of Plant Breeding and Genetics, 1, 12-18.

Kaya, Y., Akcura, M., \& Taner, S. (2006). GGE biplot analysis of multi-environment yield trials in bread wheat. Turkey Journal of Agriculture, 30, 325-337. Retrieved from http://journals.tubitak.gov.tr/agriculture/issues/tar-06-30-5/tar-30-5-3-0604-6.pdf

Lewthwaite, S. L., \& Triggs, C. M. (2012). Sweetpotato cultivar response to prolonged drought Agronomy New Zealand, $\quad 42, \quad 1-10 . \quad$ Retrieved from http://www.agronomysociety.org.nz/uploads/94803/files/1._Sweetpotato_cultivar_response_to_prolonged_d 
rought.pdf

Lisar, S. Y. S., Motafakkerazad, R., Mosharraf, M. H., \& Rahman, I. M. M. (2012). Water Stress in Plants: Causes, Effects and Responses. Retrieved from http://www.intechopen.com/books/water-stress/water-stress-inplants-causes-effects-and-responses.

Ludlow, M. M., \& Muchow, R. C. (1990). A critical evaluation of traits for improving crop yields in water

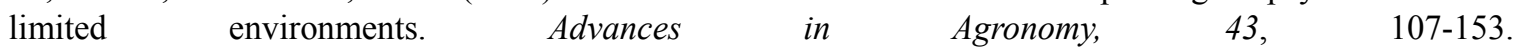
http://dx.doi.org/10.1016/S0065-2113(08)60477-0

Makihara, D., Tsuda, M., Hirai, Y., \& Kuroda, T. (1999). Effects of saline irrigation at various growth stages on rice yield. Japanese Journal of Crop Science, 68, 487-494. http://dx.doi.org/10.1626/jcs.68.487

Mohammadi, R., \& Amri, A. (2013). Genotype x environment interaction and genetic improvement for yield and yield stability of rainfed durum wheat in Iran. Euphytica, 192, 227-249. http://dx.doi.org/10.1007/s10681-012-0839-1

Mwacharo, J. M., Okeyo, A. M., Kamande, G. K., \& Rege, J. E. O. (2004). Assessment of the effectiveness of the Daltons weigh band and body measurements in estimating live weights for small east African zebu cattle in Kenya. Demand driven agricultural research for sustainable natural resource base, food security and incomes (pp. 355-358). Proceedings of 8th KARI Biennial Scientific Conference. Technical Publications Committee.

Ndegwa, A. M., Muchui, M. N., Wachuri, S. M., \& Kimamira, J. N. (2009). Evaluation of introduced snap bean (Phaesolus vulgaris L.) varieties for adaptability and pod quality (p. 4). KARI-CIAT report.

O'Geen, A. T. (2012). Soil water dynamics. Nature Education Knowledge, 6, 12. Retrieved from http://www.nature.com/scitable/knowledge/library/soil-water-dynamics-59718900

Rashidi, M., Farshadfar, E., \& Jowkar, M. M. (2013). AMMI analysis of phenotypic stability in chickpea genotypes over stress and non-stress environments. International Journal of Agriculture and Crop Sciences, 5, 253-260. Retrieved from http://eprints.icrisat.ac.in/id/eprint/11524

Ray, J. D., Yu, L., McCouch, S. R., Champoux, M. C., Wang, G., \& Nguyen, H. T. (1996). Mapping quantitative trait loci associated with root penetration ability in rice (Oryza sativa L.). Theoretical and Applied Genetics, 92, 627-636. http://dx.doi.org/10.1007/BF00226082

Sibiya, J., Tongoona, P., \& Derera, J. (2013). Combining ability and GGE biplot analyses for resistance to northern leaf blight in tropical and subtropical elite maize inbred lines Euphytica, 191, 245-257. http://dx.doi.org/10.1007/s10681-012-0806-x

Singh, K. P., Malhotra, R. S., Halila, M. H., Knights, E. J., \& Verma, M. M. (1994). Current status and future strategy in breeding chickpea for resistance to biotic and abiotic stresses. Euphytica, 73, 137-149. http://dx.doi.org/10.1007/BF00226082

Sullivan, J. A., Yan, W., \& Prive', J. P. (2002). Genotype/genotype x environment biplot analysis for cultivar evaluation and mega environmnet investigation in primocane-fruiting red raspberry. Journal of American Society Horticultural Science, 127, 776-780.

Walters, C., Farrant, J. M., Pammenter, N. W., \& Berjak, P. (2002). Desiccation stress and damage. In M. Black, H. W. Pritchard (Eds.), Desiccation and survival in plants: drying without dying (pp. 263-293). CABI publishing, Oxford and New York. http://dx.doi.org/10.1079/9780851995342.0263

Wang, J., Rich, P. M., \& Price, K. P. (2003). Temporal responses of normalised difference vegetable index (NDVI) to precipitation and temperature in the central great plains, USA. International Journal of Remote Sensing, 24, 2345-2364. http://dx.doi.org/10.1080/01431160210154812

Yan, W. (2001). GGE biplot - windows application for graphical analysis of multi-environment trial data and other types of two way data. Agronomy Journal, 93, 1111-1118. http://dx.doi.org/10.2134/agronj2001.9351111x

Yan, W., \& Hunt, L. A. (2001). Interpretation of genotype by environment interaction for winter wheat yield in Ontario. Crop Science, 41, 19-25. http://dx.doi.org/10.2135/cropsci2001.41119x

Yan, W., Kang, M. S., Ma, B., Woods, S., \& Cornelius, P. L. (2007). GGE biplot versus AMMI analysis of genotype by environment data. Crop Science, 47, 641-653. http://dx.doi.org/10.2135/cropsci2006.06.0374 
Zobel, R. W., Wright, M. J., \& Gauch, H. G. (1988). Statistical analysis of a yield trial. Agronomy Journal, 80, 388-393. http://dx.doi.org/10.2134/agronj1988.00021962008000030002x

\section{Copyrights}

Copyright for this article is retained by the author(s), with first publication rights granted to the journal.

This is an open-access article distributed under the terms and conditions of the Creative Commons Attribution license (http://creativecommons.org/licenses/by/3.0/). 